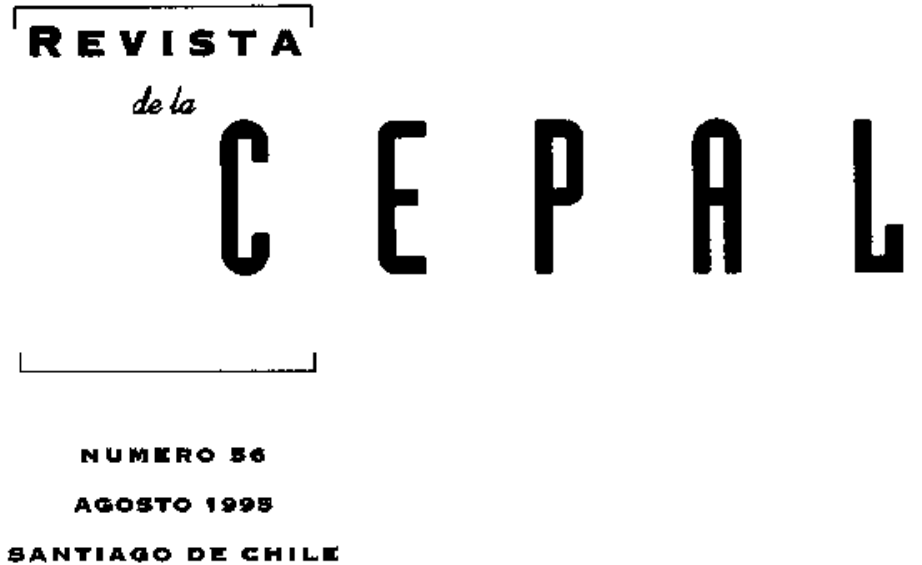

ANIBAL PINTO

Director

EUGENIO LAHERA

Secretario Técnico

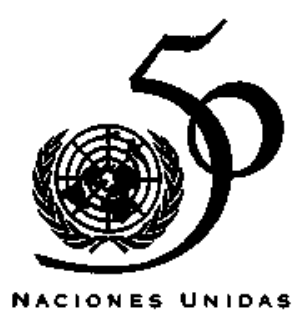


Democracla y desarrollo

Fernando H. Cardoso

¿Es posible crecer con equidad?

Joseph Ramos

Estabilidad y estructura: Interacclones en el crecimiento económlco

Jose Maria Fanelli y Roberto Frenkel

Reforma a los sistemas de pensiones en América Latina

Andras Uthoff

Tendenclas económicas en China: significado para el comerclo con América Latina y el Caribe

Mikio Kuwayama

El Intercamblo económico entre América Latina y las

economias dinámicas de Asla

Ronald Sprout

La relación económica entre la Amórica Latina y la Unlón Europea

Roberto Smith Perera

Nuevas implicaclones de las reglas do orlgen

Eduardo Gitli

Globalización y reestructuración energética en Amórlca Latina

Fernando Sánchez Albavera

El caloidoscoplo de la competitlvidad

Geraldo Muller

La privatización de los servicios públicos del agua

Miguel Solanes

¿Cuénto se puede gastar en educaclón?

Guillermo Labarca

Mujeres y migranteo: deslgualdades en el

mercado laboral de Santlago de Chile

Ivonne Szasz

Orlentaciones para los colaboradores de la Rovista de la CEPAL 


\section{Nuevas implicaciones de las reglas de origen}

\section{Eduardo Gitll}

\author{
Experto internacional \\ en politica comercial y \\ negociaciones intemacionales. \\ Asesor Técnico Principal y \\ Consultor de la UNCTAD. \\ Profesor Visitante del Centro \\ Internacional en Polftica \\ Económica para el Desarrollo \\ Sostenible. Universidad \\ Nacional, Costa Rica.
}

El tema de las reglas de origen en las negociaciones internacionales, que despierta interés desde principios de los años setenta, ha sido percibido en los últimos affos como una nueva forma de proteccionismo y ha destacado en la oleada de negociaciones comerciales que se han abierto o profundizado en el continente americano desde fines de los años ochenta. Los esquemas negociados en los nuevos tratados permiten extender la protección en los insumos intermedios de uno de los paises hacia el otro. Por lo tanto, las ventajas de una zona de libre comercio no dependen ya sólo del sistema de protección de cada país, sino también de que las barreras de sus socios comerciales sean bajas. Por otra parte, quien gana el acceso al mercado de su socio deberá "compartir la preferencia" con quien se beneficia de la regla de origen en el otro país. Mientras más pequeño sea el país que negocia, más atenazado estará si acepta reglas de origen restrictivas. Más aún, el sistema de negociaciones "uno a uno" tiene el defecto de impedir la acumulación en las reglas de origen, lo que desalienta las inversiones privadas. Frente a esta situación se ha sugerido la conveniencia de una negociación conjunta, a nivel latinoamericano, de las reglas de origen. En opinión del autor, llegar a niveles de precision individual de las normas no parece factible en las condiciones actuales. En cuanto a las reglas generales, es difícil que se avance más allá de lo acordado en la Ronda Unuguay, lo que tampoco dice mucho. De allí que sería más importante trabajar sobre un concepto de asimetría que permitiera comprender que más allá de un problema de niveles de desarrollo existe otro de tamaño relativo de los países, del que derivan profundas diferencias en las articulaciones de los eslabonamientos productivos. 


\section{I \\ Introducción}

El llamado de atención sobre las barreras no arancelarias se hizo popular a partir del momento en que las sucesivas rondas de negociaciones multilaterales fueron reduciendo los aranceles de los países desarrollados en los años sesenta y setenta, a pesar de que esas barreras existían desde mucho antes. El combate contra el dumping desde los países latinoamericanos sólo comenzo a fines de los ochenta ( $\mathrm{y}$ en algunos países de hecho aún no ha comenzado), aunque el dumping es tan viejo como el propio comercio intemacional. Esto se debe a que la apertura comercial ha aumentado la exposición de los países. Lo mismo puede decirse de las reglas de origen a medida que los procesos de apertura recíproca se hacen más complejos y estas normas aparecen como nuevos instrumentos de protección. Este artículo pretende agregar algunas reflexiones acerca de qué es lo que se está negociando y hacia donde nos están conduciendo los nuevos es. quemas que están emergiendo.

Las reglas de origen son un conjunto de normas que determinan dónde se ha producido un bien. En condiciones normales de comercio entre naciones esta información tendría poca importancia, o la tendría sólo para fines estadísticos. Sin embargo, en muchos casos los flujos de comercio de bienes están sujetos a tratamientos en frontera diferentes según el producto y según su procedencia.

El hecho de que un bien $A A$ se traslade desde un territorio del país $X X$ hacia el territorio del país $Y Y$, luego de que una empresa situada en el país $X X$ se lo vendiera a una del país $Y Y$, no otorga al bien $A A$ el carácter de originario del país $X X$. Aunque desde el punto de vista de la aduana el registro indica que el producto proviene del país $X X$, y de este modo llega a las estadísticas de comercio exterior, pueden darse muchas circunstancias en las cuales el tratamiento aduanero dependerá de cómo se considere este origen. Veamos algunos ejemplos:

i) Bajo el régimen del Acuerdo Multifibras, los países industrializados imponen cuotas a la importación de productos textiles y vestuario provenientes de países en desarrollo. Algunos de los países afectados podrían tratar de colocar sus productos a través de un tercer paśs que no tenga un nivel elevado de exportaciones de bienes de este tipo y así evadir la cuota. Y para hacer más difícil la detección podría someter el producto final a alguna transformación insignificante, como un cambio de etiqueta o empacado. Se requieren entonces normas para determinar qué conjunto de operaciones de transformación pueden alterar la "nacionalidad" de una mercancía a fin de que pueda aspirar a beneficiarse de una cuota en esta rama.

ii) Dos países crean una zona de libre comercio entre ellos, pero mantienen frente al resto del mundo sus aranceles originales, los cuales - supongamos- son diferentes. En este caso es obvio que, de no existir normas de origen, los productos entrarán a la zona a través del país que tenga el arancel menor y de allí serán trasladados al país con el arancel mayor. Como en el caso anterior, para evitar que la maniobra se descubra, el empresario de fuera de la zona podría efectuar alguna transformación pequeña para evadir los controles aduaneros. Determinar si estas transformaciones son suficientes para convertir insumos importados en un producto nacional susceptible de ser comerciado dentro de la zona sin causar aranceles es un objetivo de la reglas de origen.

iii) El Acuerdo General sobre Aranceles Aduaneros y Comercio (GATT) concede el trato de nación más favorecida a las naciones participantes. Países como Estados Unidos mantienen un arancel aún superior para los países que no son miembros o para aquellos a los que, por razones políticas, no desea dar ese trato (Vietnam, por ejemplo). En este caso, se necesitan criterios para aplicar el arancel correspondiente.

En cada una de estas situaciones pudiera ser que estuviéramos hablando de diferentes normas de origen, incluso para un mismo país aplicante. Más aún, las normas de origen suelen ser diferentes en diversos paises y situaciones. Retomaremos este tema más adelante. 


\section{II}

\section{Tipología de las normas de origen}

Aunque es poco sabido, la tipología actual de las normas de origen fue establecida con la firma del Convenio Internacional de Kyoto del 18 de mayo de 1973 para la simplificación y armonización de los trámites aduaneros. Este Convenio, elaborado bajo los auspicios del Consejo de Cooperación Aduanera, establece una serie de medidas tendientes más bien a organizar futuras actividades en estas materias. Lo verdaderamente de interés para nuestro tema radica en el anexo D.1 del Convenio, relativo a las reglas de origen, porque en lo esencial poco o nada ha cambiado desde esas "antiguas" definiciones. 1

Los criterios establecidos allí son dos: primero, si el artículo ha sido enteramente producido en un país determinado, ya sea mediante labores más o menos primitivas de extracción, cosecha, pesca, etc. o utilizando insumos que a su vez han sido producidos en el país, no hay dudas acerca del origen nacional de los productos,

Segundo, si en el artículo ha intervenido más de un país, ya sea con materiales o mano de obra, para que el producto adquiera una nacionalidad específica debe existir una "transformación sustancial" que puede definirse de diversas maneras: i) por la regla del cambio de partida arancelaria; ii) por la lista de transformaciones o de elaboraciones que confieren o no a las mercancías que las han sufrido la calidad de originarias del país donde ellas se han efectuado, y iii) por la regla del porcentaje ad valorem cuando el porcentaje del valor de los productos utilizados o el porcentaje de la plusvalía adquirida en el país se conforma a un nivel determinado.

Existe una modalidad anterior que no fue especificada en Kyoto: la de aplicar porcentajes de contenido que no sean ad valorem, fundamentalmente en el caso de mezclas (por ejemplo, contenidos de peso en lanas, o de volumen en mezclas de jugos). En el Tratado de Libre Comercio de Norteamérica abundan ejemplos de este sistema.

El anexo D.1 del Convenio no define siquiera de

1 El anexo D.1 del Convenio Internacional de Kyoto establece las definiciones más generales de distintas normas de origen y evalúa sus ventajas e inconvenientes, pero no determina un conjunto óptimo de normas y procedimientos. manera abstracta el concepto de "transformación sustancial", que aparece entre comillas en el original. El servicio de aduanas de Estados Unidos entiende que hay "transformación sustancial" cuando un artículo adquiere a través de un proceso productivo un nombre, características y uso diferentes al de los materiales utilizados en su elaboración. A continuación examinaremos las tres posibilidades de esa transformación.

\section{Cambio de partida o salto arancelario}

En sus términos más sencillos, el concepto de salto arancelario establece que una mercancía es originaria cuando el producto final se ubica en una posición arancelaria diferente a la de sus insumos intermedios importados. El sencillo encanto de esta definición desaparece cuando tenemos en cuenta que el punto de partida actual para las clasificaciones de mercancías es el Sistema Armonizado de Designación y Codificación de Mercancías, cuya elaboración obedece a consideraciones de identificación aduanera y de estadística y a criterios amplios de transformación. La vida productiva es mucho más rica que la agregación del Sistema Armonizado. El "salto arancelario" puede darse entre capítulos (dos dígitos), partidas (cuatro dígitos), subpartidas (6 dígitos), o fracciones de 8 o hasta de 10 dígitos.

El problema no surge de la aplicación del Sistema Armonizado, que es mucho más nuevo que el Convenio Internacional de Kyoto, sino de la concepcion original de este criterio, en 1973, cuando se pensaba que el "salto arancelario" podría tomar la forma de una regla general (no existía suficiente experiencia práctica al respecto), por ejemplo, definiendo el "salto" como el cambio de una partida (cuatro dígitos) a otra, más una lista de excepciones. La realidad ha resultado más compleja.

Evidentemente, definir un "salto arancelario" como el paso de un capítulo a otro (hay 97 capítulos en el Sistema Armonizado) es un criterio demasiado estrecho. Puede haber dos productos dentro de una misma partida uno de los cuales sea insumo del otro y entre los cuales exista una buena dosis de transformación. Por ejemplo, dentro del capítulo 95 "Juguetes" es posible imaginar un juguete que sea combina- 
ción de varias piezas, por ejemplo, "Juguetes que representen animales" (9503.30) y que junto a modelos de pesebres y figuras humanas de fabricación y empaque nacionales se transformen en "Artículos para fiestas de Navidad" (9505.10). A simple vista es obvio que el bien final ha sufrido una transformación sustancial. Sin embargo, si el producto final estuviera en la misma partida que uno de sus insumos importantes (9503) - por no haberse podido calificar como "de Navidad", por ejemplo- permanecería en la misma partida y por lo tanto no podría calificar. Por motivos como éste, el salto arancelario es definido caso a caso por los negociadores de tratados de cada país, y aquí entran en juego los diversos intereses empresariales. $^{2}$

\section{Lista de transformaciones o elaboraciones}

En este método se utilizan normalmente listas generales que describen, producto por producto, los procedimientos técnicos de suficiente importancia. Este criterio ofrece ventajas porque permite uniformar criterios cuando las tareas son lo bastante generales. No obstante, la variedad de casos y la complejidad de los procesos productivos dificulta mucho su utilización. Aunque este criterio se aplica más bien en su aspecto positivo, todo conjunto de normas de origen mantiene una lista de operaciones que no confieren al producto la calidad de originario (por ejemplo, ensamblado, diluido, etc.).

\section{Regla del porcentaje ad valorem}

Este procedimiento para la determinación del origen de las mercancías parece ser el más sencillo y aunque ha sido objeto de muchas controversias, es uno de los más usados. Parece natural, y lo más razonable, equiparar el concepto de "transformación sustancial" a un cambio equivalente de su valor de mercado. Cualquiera sea la complejidad de los procesos productivos o de los cambios arancelarios, tiene que haber un criterio de valor para determinar cuando un producto ha sido suficientemente "transformado". El valor agregado por la transformación se puede calcular como

\footnotetext{
2 De hecho, una de las primeras quejas por problemas de interpretación de las reglas de origen del Tratado de Libre Comercio de Norteamérica se refirió al caso de los juguetes. Bajo las normas de origen del Sistema Generalizado de Preferencias éstos no tenían obstáculos para ingresar desde México a Estados Unidos, pero con el criterio del salto arancelario encontraron dificultades (Joumal of Commerce, 1 de mazzo de 1994).
}

un porcentaje mínimo del valor total del bien que haya sido generado dentro del pars. Por ejemplo, el Sistema Generalizado de Preferencias de los Estados Unidos, la Iniciativa para la Cuenca del Caribe y el Acuerdo de Libre Comercio de los Estados Unidos con Israel establecen como criterio un $35 \%$ de contenido nacional mínimo para el conjunto de materiales y costos directos de operación. Otros acuerdos, como la Asociación Latinoamericana de Integración (ALADI) y el viejo Tratado de Libre Comercio de los Estados Unidos con Canadá, establecen un $50 \%$. Volveremos sobre estos temas más adelante.

A este procedimiento se le han hecho muchas críticas que conviene tener presente:

i) Surgen dificultades en los casos límites en que una pequeña diferencia puede determinar el origen del producto.

ii) En muchos casos estas diferencias provienen de cambios en los precios relativos del producto final respecto de los diversos insumos, que pueden deberse a cambios en los precios internacionales o a fluctuaciones monetarias.

iii) Hay una importante objeción que sólo salta a la vista en compromisos no unilaterales. La diferencia de costo de la mano de obra entre países con diferente grado de desarrollo resulta en diferentes porcentajes de valor agregado nacional, y puede llevar a su vez a la contradicción de que un mismo producto, resultado inclusive de procesos tecnológicos similares, califique como originario cuando es hecho en Estados Unidos, pero no cuando es producido en México (Morici, 1991). Esta es una objeción que surge cuando el criterio de valor agregado se aplica recíprocamente entre países con grandes diferencias salariales.

iv) Se tropieza con dificultades debido a que las primeras definiciones de "contenido nacional" eran conceptualmente claras, pero poco precisas para el cálculo empresarial. En particular, al sumar "costo de materiales más el costo directo de procesamiento" surge el problema de definir contablemente este último concepto, que debe incluir los costos laborales más los costos de capital asignables (depreciación, renta imputada a la tierra). Los costos generales difíciles de imputar quedan definitivamente fuera del cálculo. Por último, es diferente calcular el contenido nacional residualmente (valor total menos contenido importado) que hacerlo "directamente" (materiales nacionales más costo directo de las operaciones); en este último caso hay serios problemas de definiciones.

En suma, no existe un criterio único para definir el concepto de transformación sustancial; más bien 
existen intereses y estos se expresan en combinaciones de criterios. Si la determinación de la calidad de originario depende de los negociadores gubernamentales, las presiones de los intereses sectoriales privados asumirán gran importancia en las negociaciones. $Y$ aquí es donde todo se complica. Desde un punto de vista técnico, es más sencillo discutir plazos de desgravación (0, 5 y 10 años, y 15 en casos muy excepcionales), porque aunque los empresarios traten de ejercer su influencia, tarde o temprano deberán caer en una de esas categorías y llegar - a través de un proceso más largo o más corto- a un arancel cero. En cambio, las combinaciones para definir normas de origen son múltiples y permanecen para siempre, o hasta que se renegocien.

Cabe destacar que en estos casos el concepto de "transformación sustancial" no responde a principio alguno claramente medible. ${ }^{3}$ Son los negociadores nacionales los que la definen, negociando entre ellos las presiones de sus propias industrias.

\section{III}

\section{El arco iris de las normas de origen}

Como se dijo antes, todo acuerdo de trato especial ante barreras arancelarias o no arancelarias, va acompañado de los criterios correspondientes para determinar el origen de las mercancías.

\section{Acuerdo General sobre Aranceles Aduaneros y Comercio (CATT)}

Aunque pocos ven hoy en día al GATT y a su sucesora, la Organización Mundial de Comercio (OMC), como clubes de comercio preferencial, en realidad lo son, en la medida en que los compromisos se deben respetar solo entre países participantes.

En la Ronda Uruguay se negocio un Acuerdo sobre Normas de Origen que se refiere solamente a lo que el GATT denomina - paradojicamente-m "instrumentos de política comercial no preferenciales" (artículo 1) partiendo del principio de nación más favorecida. Esto es, ellos se aplican en el caso de los derechos generales del GATT, pero no a los acuerdos preferenciales como el SGP. El compromiso es armonizar las normas de origen entre los países en un periodo de tres años. Para ello se crea un Comité de Normas de Origen y un Comité Técnico, que actuarán bajo los auspicios del Consejo de Cooperación Aduanera.

Los criterios dominantes para establecer origen serán los siguientes: i) que los artículos hayan sido producidos enteramente en un país determinado; ii) que haya habido una transformación sustancial que determine un cambio de clasificación arancelaria, y iii) que en los casos en que los dos criterios anteriores no sean suficientes, se pueda acudir a criterios de porcentajes de valor o de operaciones de elaboración.

\section{Slstema Generalizado de Preferenclas (SGP)}

No existe en este caso una norma internacional. En el SGP de los Estados Unidos se requiere que "el costo o valor de los materiales producidos en el país en desarollo beneficiario o en dos o más países que sean miembros de la misma asociación... más el costo directo de las operaciones de elaboración realizadas en tales países, no resulte inferior al $35 \%$ del valor estimado de dicho artículo en el momento de su entrada al territorio" de los Estados Unidos. Hay aquí varias incógnitas, como el concepto de "valor estimado" y el propio concepto de "costo directo de las operaciones", al cual se hizo referencia anteriormente.

\section{Iniciativa para la Cuenca del Carlbe (ICC)}

En este esquema la normativa es muy similar a la del SGP, con una diferencia importante: dentro del $35 \%$ de contenido nacional se acepta la posibilidad de que 15 puntos porcentuales correspondan a contenido estadounidense. Dentro de los costos directos de operación no pueden incluirse ni utilidades ni gastos generales, pero sí la depreciación de maquinaria y equipo cuando se pueda asignar al producto en cuestion.

El anexo II al Acuerdo sobre Normas de Origen del Acta de Marrakesh" es una "Declaración común

\footnotetext{
3 Basta con recordar las normas de origen para los productos del sector vestuario en el Tratado de Libre Comercio de Norteamérica, por las cuales la calidad de originaria de una prenda de vestir se determina "desde el hilado" en adelante.

4 En el cual se incorporan los resultados de la Ronda Uruguay de Negociaciones Económicas Multilaterales (abril de 1994).
} 
acerca de las normas de origen preferenciales" que no aporta nada trascendental en sus dos hojas, más allá de hacer referencia a la necesidad de que esas normas estén claramente especificadas, los métodos de cálculo sean transparentes, etc. No establece ningún principio rector.

\section{Mercado Común Centroamerlcano (McCA)}

En el caso de los países signatarios del Tratado General de Integración Economica Centroamericana, el Reglamento sobre el Origen Centroamericano de las Mercancías es bastante permisivo. Es necesario tener en cuenta, que a diferencia de las otras zonas de libre comercio del continente americano, ésta es una unión aduanera. Según sus normas, son originarios i) los productos "naturales" de cualquiera de los Estados miembros; ii) las mercancías fabricadas a partir de ellos; iii) las que contienen insumos importados que "hayan sufrido un proceso de produccion que les confiera una nueva individualidad que dé lugar a un "salto arancelario" (no se define el tipo de saito); iv) de no ser suficiente el criterio anterior, se utilizará el criterio de un mínimo de $25 \%$ de contenido regional en materia de costos directos. Quedan expresamente excluidos de la definición los productos que hayan sido simplemente armados, envasados, diluidos, etc. En 1995 se está discutiendo un nuevo reglamento que hará del salto arancelario el eje de la transformación sustancial. No obstante, el porcentaje de contenido regional mínimo sigue causando polémica.

\section{Asociación Latinoamericana de Integración (ALADI)}

Los países firmantes del Tratado de Montevideo de 1980 tienen un conjunto de normas de origen un poco más elaboradas. Los artículos se consideran originarios si i) son producidos enteramente en el pais; ii) si han sufrido un cambio de clasificación arancelaria; iii) si el valor cif de los materiales originarios de terceros países no excede el $50 \%$ del valor de exportación fob de las mercancias, iv) si los bienes cumplen con otros requisitos específicos, como la obligación de utilizar insumos de los países signatarios. El Acuerdo de Complementación Económica entre Chile y México firmado en septiembre de 1991 reconoce expresamente las normas de origen de la ALADI, aunque permite a la Comisión Administradora establecer requisitos específicos y, por ende, se lo encomienda. El Mercosur también aplica requisitos similares a los de la AlADI.

\section{Estados Unidos}

Antes de suscribir al acuerdo de libre comercio con Canadá en 1989, Estados Unidos no había publicado regla alguna de origen, salvo las más generales aplicables al SGP, a la Iniciativa para la Cuenca del Caribe y al Acuerdo de Libre Comercio con Israel. Cuando se presentaba algún problema, las decisiones eran tomadas caso a caso por los oficiales aduaneros, aplicando principios generales elaborados a lo largo de muchos años. S6́lo al suscribir grandes acuerdos de comercio Estados Unidos se vio enfrentado por primera vez al problema de la necesaria bilateralidad de las normas (tanto en su calidad de exportador como en la de importador). En el acuerdo con Canadá se utilizó el criterio del cambio de clasificación arancelaria $\mathrm{y}$, alternativamente, el del $50 \%$ de valor agregado nacional en forma bastante abstracta y poco clara. En el acuerdo con Israel se aplicó un criterio similar al del SGP, sólo que con vigencia para ambos lados.

\section{IV}

\section{Las normas de origen en el Tratado de}

\section{Libre Comerclo de Norteamérica (TLCN)}

\section{Definiciones generales}

Las reglas de origen de este tratado se definen y explican en las 26 páginas correspondientes al capítulo cuatro de su volumen 1 . No obstante, la descripción detallada de los saltos arancelarios específicos se encuentra en 168 páginas del volumen 2 . La definición general de un bien originario del territorio de una Parte es la siguiente:

i) El bien es obtenido enteramente en el territo- 
rio de una o más de las Partes (minerales, vegetales, animales nacidos y criados, caza y pesca, etc.).

ii) Cada uno de los materiales no originarios utilizados en la producción de un bien ha cambiado de clasificación arancelaria de acuerdo con la lista espećffica establecida en el volumen 2 del Tratado, o en caso de no necesitarse cambio arancelario, satisface los demás requisitos establecidos.

iii) El bien es producido en el territorio de una o más de las Partes con materiales exclusivamente originarios. ${ }^{5}$

iv) El bien es producido en una o más de las partes, pero algunos de los materiales no originarios usados en la producción no ha cambiado de clasificación debido a que fue clasificado como ensamblado de acuerdo con las reglas del Sistema Armonizado, o la clasificación arancelaria incluye el artículo final y sus piezas sueltas. En este caso se utiliza la siguiente regla: el valor regional contenido en el bien debe ser superior o igual al $60 \%$ del valor de transacción (FOB), o superior al $50 \%$ del costo neto (la elección corresponde al exportador, a menos que esto no sea aplicable por diversas razones, entre otras la no independencia de las partes). ${ }^{6}$ Los productos pertenecientes a los capítulos 61-63 "Vestuario" están excluidos de esta regla.

\section{Los automóviles: exigencla de un porcentaje creclente de valor regional}

Las negociaciones en torno a la industria automotriz fueron difíciles debido a que Estados Unidos y México son sensibles a su impacto en la ocupación y las exportaciones. Una parte muy importante (entre el 30 y el $40 \%$ ) de la expansión de las exportaciones mexicanas en los últimos 10 años se debió a la industria automotriz (motores y automóviles). Estados Unidos insistió en que los vehículos llevaran el máximo posible de contenido nacional para ser declarados origi-

\footnotetext{
5 Cabe subrayar que - a diferencia, por ejemplo, de la ICC- en el TLCN los tres territorios se consideran uno solo. De manera que una fábrica mexicana que utilice exclusivamente materiales canadienses califica igual que si ellos fueran de su propio país. Para el TLCN los conceptos de región y país son intercambiables en materia de normas de origen.

6 Hay varias circunstancias en las que se debe optar forzosamente por el método del costo neto; por ejemplo, en el caso de vehículos. El método del valor de transacción es sumamente sencillo cuando el porcentaje de contenido nacional surge de la diferencia entre el valor de la transacción y los materiales importados. El cálculo en el método del costo neto responde a la misma fórmula: el costo neto se utiliza en vez del valor de transacción, y en este caso excluye la promoción, comercialización, regalías, empaque, etc.
}

narios. Por este motivo, aparte de cualquier requisito de salto arancelario, se estableció que, de caer los vehículos en las condiciones señaladas en el inciso iv) del apartado 1 anterior, y partiendo con un $50 \%$ de valor regional calculado por el método del costo neto, ese valor debería ser de $56 \%$ en 1998 y de $62.5 \%$ en 2002 (o de 50,55 y $60 \%$ en otro tipo de vehículos).

\section{Porcentaje de $\mathrm{m} / \mathrm{h} / \mathrm{m} / \mathrm{s}$}

En la vida cotidiana hay muchos casos de utilizacion de insumos importados que no sufren una transformación arancelaria como la requerida por la lista específica, pero cuyo impacto sobre el producto final es poco significativo. En este caso, se establece una regla (artículo 405) por la cual un bien puede considerarse originario si el valor de los materiales no originarios contenidos en su producción y que no sufren cambio de clasificación arancelaria no supera el $7 \%$ del valor fob de transaccion. ${ }^{7,8} \mathrm{Al}$ igual que en el caso del porcentaje de contenido regional, el de minimis puede expresarse en porcentaje de contenido en volumen o peso.

\section{Comprobación del orlgen}

El capítulo 5 del TLCN trata de los procedimientos aduaneros, que en su mayoría se refieren al Certificado de Origen. Como interesante innovación, quien firma el Certificado de Origen y se responsabiliza por él es el exportador, y no el productor, el gobiemo, las cámaras de comercio, etc. Esto simplifica los trámites, retomando así las tendencias modernas de las nomativas del comercio internacional: i)sobre el comerciante recae toda la responsabilidad, ii) se le debe creer hasta que se demuestre lo contrario, y iii) el riesgo de ser sorprendido en infracción, multiplicado por el castigo elevado al que se hace acreedor, desalienta las infracciones. Por lo demás, se ha llegado a la comprobación práctica de que la emisión de Certificados de Origen por entidades oficiales no agrega el suficiente grado de confiabilidad, y que el exportador, en caso de ser sorprendido en infracción, suele repartir la responsabilidad con autoridades del país de origen, creando fricciones innecesarias entre las naciones signatarias.

\footnotetext{
7 Esta norma no se aplica en un conjunto específico de casos: algunos productos lácteos, jugos, café instantáneo y otros.

8 Los "materiales indirectos" se consideran automáticamente como originarios (gasolina, lubricantes, etc).
} 


\section{Reglas especificas y saltos arancelarios}

Las reglas específicas para el salto arancelario se establecen en el volumen II del Tratado de Libre Comercio de Norteamérica. Se presentan en dos columnas. En el lado izquierdo se registra la partida, subpartida o fracción arancelaria, y en el lado derecho se especifica qué se entiende por salto arancelario en cada caso particular. En ciertos bienes, la especificación es tan sencilla que se hace sólo a nivel de cuatro dígitos y en otras, de seis. En la columna de especificaciones del salto arancelario éstas se hacen muchas veces a nivel de ocho dígitos.

Por ejemplo, en el capítulo 2, "Carne y despojos comestibles", el criterio para otorgar la calidad de originario es, respecto de todas las partidas, que el insumo provenga de otro capítulo. En sentido estricto esto significa que aunque el animal vivo se importe, el acto productjvo de la matanza confiere origen.

En el caso de la reglas de origen para la rama textil y del vestuario se aprecia mejor la arbitrariedad con que se negocian estas reglas en relación con cualquier concepto lógico de lo que es "transformación sustancial". Dentro del Sistema Armonizado, los capítulos correspondientes van del 50 al 63, aunque las prendas de vestir están incluidas en los capítulos 61 y 62 y algunas en el 63 . El criterio general para conferir origen en el TLCN es el del "hilado hacia arriba", el que a veces se vuelve más estricto y otras menos, dependiendo de la pauta de protección que se aplique. Por ejemplo, el hilado de lana (SA 51.06) puede ser producido con lana importada (SA 51.01), pero el hilado de algodón no puede ser producido con algodón importado (tiene que provenir de alguno de los tres países del TLCN).

Desde los tejidos en adelante, ya se exige que el hilado provenga de la región, con un par de excepciones. Por ejemplo, los tejidos de seda (partida 50.07) pueden provenir de cualquier otra partida. El hilado de seda está en la partida 50.04, lo cual significa que un cambio de partida dentro del mismo capítulo confiere la calidad de originario. El tejido de seda producido en los países de la región a partir de hilados de seda importados es entonces originario. La lógica de esta determinación radica en que, al no existir producción suficiente de esas fibras en la región, nadje tiene algo que proteger.

A su vez, las prendas de vestir deben utilizar tejidos fabricados en la región, con lo cual cerramos el circuito (véase el anexo 1).<smiles>[AlH2]</smiles>

\section{Las normas de origen como instrumentos}

\section{de la nueva protección}

Casi por definición, las zonas de libre comercio tienen un sesgo que no está presente en las uniones aduaneras. Recordemos que en la tradición latinoamericana (que está cambiando aceleradamente), estas últimas no son más que zonas de libre comercio que tienen un arancel común frente a terceros países. Distingamos tres casos.

\section{Unión aduanera perfecta}

Una unión aduanera perfecta es aquélla en la cual los países asociados de este modo poseen un sistema aduanero, común o no, pero con un acuerdo previo de distribución entre los países de lo que se recaude ? $^{9}$

\footnotetext{
9 En el caso de la Unión Europea (UE), la administración aduanera es común y todos los ingresos por concepto de aranceles entran a la bolsa comín de la UE. La utilizacion posterior de estos fondos
}

En tal caso, da lo mismo por qué país y aduana entra el bien importado a la UE, sea insumo o bien final, ya que con posterioridad puede circular libremente en su interior. Las reglas de origen, por lo tanto, son totalmente innecesarias.

\section{Unlón aduanera simple}

En una unión aduanera simple, como cualquiera de las latinoamericanas, el producto que entra por la aduana del país $X X$ no puede pasar al país $Y Y$ porque quien ha recaudado el arancel externo "común" (pero no socializado) es el fisco del país $X X$. Lo mismo

en programas conjuntos de la UE no tiene nada que ver con el origen de la recaudación. De esta manera, el origen de las mercancías pierde importancia. 
ocurre con los insumos importados. Por este motivo, las uniones aduaneras en América Latina tienen reglamentos sobre origen o sobre "dudas de origen". La motivacion fundamental de mantener estas disposiciones es meramente recaudatoria.

\section{Zona de llbre comercio}

En una zona de libre comercio, cada nación mantiene su arancel particular frente al resto del mundo. En este caso habría dos problemas:

i) los bienes terminados buscarían entrar a la zona a través del país con aranceles menores, para luego ser reexportados intemamente sin aranceles, y

ii) los productores de países cuyos insumos tienen aranceles menores tendrían una ventaja competitiva frente a sus homólogos de los países asociados. El exportador de fuera de la zona podría hacer entrar su producto final en una etapa de procesamiento anterior, finalizarlo en el país $X X$ de la zona, cuyos aranceles son menores, y reexpedirlo al país $Y Y$, que tiene aranceles más altos, tanto para el bien final como para el producto intermedio.

Problemas como los dos señalados se evitan a través de la determinación de un conjunto de notmas de origen. Y para combatir el segundo de ellos existe un instrumento adicional, que es la eliminación del sistema de reembolso del arancel pagado en el comercio recíproco.

Detengámonos brevemente en este último punto. Si el bien $A A$ se produce en el país $X X$ con un insumo $B B$ cuyo arancel es de $10 \%, y$ también se produce en el país $Y Y$, donde $B B$ tiene un arancel de $5 \%$, la costumbre internacional y el GATT ( $y$ ahora la OMC) aceptan que al exportar el producto $A A$ de $X X$ hacia $Y Y$ el exportador solicite el reembolso del arancel pagado por el insumo. Esto se debe -en términos generales- a que el producto exportado paga a su vez un arancel en el país de destino.

Pero si ambos países participan en una zona de libre comercio, el bien $A A$ entrará de $X X$ a $Y Y$ sin pagar aranceles, $y$ esto significará una desventaja para el productor del mismo bien que está radicado en el país $Y Y$, quien sí los deberá pagar. En el caso de unión aduanera, es obvio que no puede haber mecanismos de reembolso recíprocos: ambos productores pagan el mismo arancel por sus insumos y la competencia se da entonces en pie de igualdad. En una zona de libre comercio el asunto no es tan claro. En nuestro ejemplo, uno paga $10 \%$ y el otro paga $5 \%$ de arancel por los insumos, pero los bienes finales producidos se comercializan recíprocamente sin aranceles.

Tanto el Tratado de Libre Comercio de Norteamérica como el reciente entre México y Costa Rica, y otros que se están negociando en forma paralela bajo el criterio de zona de libre comercio, establecen fechas límites para eliminar el sistema de reembolso en el comercio recíproco. En el caso del TLCN, la última fecha para la eliminación del sistema es el $1^{\circ}$ de enero del año $2001 .^{10}$

Hasta ahora se ha pensado poco en el hecho siguiente: al eliminarse el sistema de reembolso en el comercio recíproco entre dos países en los cuales sea importante el uso del mismo insumo, los usuarios en el país donde el arancel es más elevado presionarán fuertemente a su gobiemo para que lo reduzca a la altura del de la otra parte, para nivelar la competencia. Esta es una razón poderosa para pensar que, de continuar la fiebre de tratados de libre comercio en América Latina, se avance hacia un arancel externo común, al menos de insumos. Lo más probable es que este arancel común tienda a la baja debido a la forma individual y no programada de cada pugna de los sectores privados con los gobiernos.

En la teoría económica convencional de la integración se hace referencia - por comodidad- solamente a los aranceles y en alguno que otro caso a la supresión de barreras cuantitativas. Se da casi por sentado que todo acuerdo de libre comercio es bueno mientras no eleve los aranceles o las barreras no arancelarias frente al resto del mundo.

Krueger (1993) señala que existe un importante sesgo proteccionista en las zonas de libre comercio que no está presente en las uniones aduaneras. El hecho de que en esas zonas los aranceles hacia afuera de la región difieran, hace necesarias las normas de origen; a través de estas normas, la protección de uno de los países miembros se extiende al otro, generando posibles desviaciones de comercio. En un texto del SELA se va más allá y se sostiene que "las normas de origen son para el TLC lo que un arancel extemo común es para la Unión Aduanera" (SELA, 1993).

El mismo estudio de Krueger subraya también que, según el enfoque convencional acerca de los efectos positivos y negativos de las zonas de libre comer-

\footnotetext{
${ }^{10}$ De hecho, estas disposiciones, junto a otras, van a afectar al sistema de maquiladoras en México por dos motivos: i) porque van a poder colocar progresivamente toda su producción en el mercado interno si así lo desean, y ii) porque desaparecerán las exoneraciones para los insumos que de todas maneras entrarán libres de impuestos en el año 2001 (Comisión de Comercio Intemacional, 1994).
} 
cio, los efectos de desviación de comercio en un país son menores en la medida en que sus propias barreras antes de suscribir el acuerdo hayan sido menores. No obstante, al introducirse el problema de las reglas de origen, también las barreras de su socio deberían ser bajas para evitar costos elevados de integración.

Como corolario de los párrafos anteriores, recordemos que la formación de una zona de libre comercio tiene efectos de creación y de desviación de comercio.

Cuando la rebaja arancelaria permite a un país importar de su socio lo que antes producía de manera menos eficiente (más cara), decimos que hay creación de un comercio que antes no existía. Si antes de la integración un país importaba cierto producto desde fuera de la región, y luego de comenzada la vigencia de las preferencias lo adquiere de su vecino (que produce más caro), hay desviación de un comercio que ya existía. En este caso se produce una ineficiencia, al pagar el país en su conjunto una mayor cantidad de dinero por el producto que adquiere en el exterior. Cierto es que el importador paga menos, pero esto se debe a que el arancel ha disminuido. Lo importante es que en este caso el país comienza a abastecerse desde una fuente más cara y menos eficiente.

Una forma de paliar esta ineficiencia es mantener un arancel bajo para el resto del mundo respecto de los productos que se importan desde los países integrantes de la zona. De esta manera, el margen de preferencia del socio de integración es menor y la desviación es también probablemente menor, dependiendo de la elasticidad-precio de los productos. Cuando la creación de comercio predomina sobre la desviación, cabe suponer que aumenta el bienestar del país. Si, por el contrario, predominan los efectos de desviación, es probable que el país pierda. ${ }^{11}$ Esto es lo tradicional en materia de estrategias de integración.

Un ejemplo extremo nos ayudará a comprender mejor todas estas situaciones. Un país con arancel cero sobre todos sus productos antes de la conformación de la zona de libre comercio no perdería absolutamente nada, ya que continuaría abasteciéndose con el proveedor de más bajo costo, en tanto que mejoraría su acceso al mercado del país con el cual se asocia. Pero si introducimos el tema de las normas de origen, un país con arancel cero sobre todos sus pro-

11 Podría haber ganancias de consumo tipo Meade si el efecto de ductos antes de la conformación de la zona de libre comercio podría verse obligado a cambiar la fuente donde adquiere sus insumos para beneficiarse del acceso al nuevo mercado.

Lo importante como conclusión es que las reglas de origen pueden extender la protección al país que produce los insumos en el mercado de su socio, al otorgarle preferencias en el bien final.

La posición de Estados Unidos durante las negociaciones del Tratado de Libre Comercio de Norteamérica fue siempre la de mantener las reglas de origen más estrictas posible. Para Krueger (1993), es evidente que Estados Unidos intentaba proteger a los productores estadounidenses en el mercado mexicano, "exportando" la protección de su país aun siendo las tasas arancelarias mexicanas bajas.

Otro ángulo desde el cual se puede analizar este efecto económico de las reglas de origen es el siguiente: el empresario que pretende exportar dentro de la región acogido a una preferencia, en realidad la está compartiendo con su abastecedor de insumos dentro del mercado regional al que apunta. Este ángulo ha sido poco percibido en las negociaciones, pero tiene un profundo interés práctico. Veamos un ejemplo numérico.

Supongamos que el arancel de un producto AA en el país $X X$ es de $15 \%$, y utiliza un solo insumo $B B$ que tiene un arancel de 7\%. Supongamos que en el país $Y Y$ ese insumo no se produce ni tiene arancel, y que participa en el costo total con un $50 \%$. Al eliminarse el arancel del producto $A A$, el margen de preferencia del país $Y Y$ en el país $X X$ será de 15 puntos porcentuales. En cambio, al verse forzado a adquirir el insumo en el país $X X$, deberá pagar un sobreprecio de $7 \%$ (suponiendo que el arancel mide adecuadamente la protección nominal implícita en $X X$ ). El fabricante ubicado en $Y Y$ tendrá que descontar de su preferencia (o posible sobreprecio) de 15 puntos porcentuales un costo adicional de $3.5(50 \% \times 7 \%)$. Por lo tanto su margen de preferencia será de 11.5 puntos porcentuales.

Evidentemente, ningún experto gubernamental podrá hilar tan fino en estos cálculos simplificados, cubriendo todos los productos. Es vital que el sector privado participe, aportando sus cálculos y calculistas, en la exploración de todos los posibles efectos de las reglas de origen. 


\section{VI}

\section{Una digresión final sobre el concepto}

\section{de asimetría}

El concepto de asimetría ha sido el más inasible de todos los que se han utilizado a la sombra de las negociaciones comerciales. Durante las negociaciones del TLCN esta palabra estuvo prohibida. La refloto el Secretario de Comercio de México, Jaime Serra Puche, solamente cuando presento los resultados, indicando que se babía conseguido un tratamiento asimétrico a favor de México (Serra Puche, 1992).

En el Acta de Tuxtla Gutiérrez del 11 de enero de 1991, que sirvió de referencia para las negociaciones comerciales entre México y los países centroamericanos, se establece que "las negociaciones para la liberación comercial tomarán en cuenta las diferencias relativas existentes en los niveles de desarrollo economico de los países participantes" (anexo al Acta). El 31 de marzo de 1992 se firmó el Acuerdo Marco Multilateral para el Programa de Liberalización Comercial entre los Gobiernos de Costa Rica, El Salvador, Guatemala, Honduras, México y Nicaragua. En sus considerandos también aparecen referencias a "sus niveles de desarrollo relativo".

Sin embargo, no se ha establecido una noción clara que sustente el concepto de asimetría. Si se compara la diferencia existente entre México y Estados Unidos en materia de población, producto nacional bruto, superficie y exportaciones, con la que se observa entre cada uno de los países centroamericanos y México y si éstos son indicadores de asimetría, queda claro que las distancias entre cada país centroamericano y México son mayores que las existentes entre México y Estados Unidos (gráfíco 1).

Los cuatro indicadores de tamaño relativo señalados debieran pesar a la hora de las negociaciones. En general, los negociadores tienden a buscar la asimetría en los plazos de desgravación. Pero estos plazos son pasajeros y llevan a nivelar el terreno en algún momento en una barrera comercial igual a cero. Los diferentes plazos de adaptación pueden ser importantes, pero las reglas de origen quedan fijas $y$ pueden determinar patrones menos eficientes de inversión en el futuro. Por ejemplo, la acumulación de países pequeños para los fines de las normas de origen puede alentar las inversiones regionales en los casos en que se requiera más de un salto arancelario para que el producto final califique. El ejemplo más típico es el del sector vestuario, donde se suele requerir, de acuerdo a las normas del TlCN, un triple salto a partir del hilo. Es difícil que un país pequeño tenga simultáneamente actividades desarrolladas de hilandería, de telas y de prendas de vestir. Por lo tanto, al negociar aisladamente con México, por ejemplo (sobre la base de las normas del TLCN), sólo podrá exportar prendas de vestir hacia ese país si está totalmente integrada la producción o si adquiere sus insumos en México. Sin embargo, de existir la posibilidad de acumulación regional, se fomentarían las inversiones centroamericanas en textiles e hilados.

Los países que tengan la posibilidad material de negociar en bloque la integración tendrán siempre más posibilidades en este sentido. Hay una ganancia a largo plazo en esa posibilidad de acumulación, que de no ser resuelta en la organización de corto plazo causará un daño bastante grande a las economías más pequeñas.

En este artículo hemos podido apreciar que no solamente se están negociando reglas de origen basadas en distintas metodologías para medir la transformación sustancial (que asignan prioridades diferentes al salto arancelario, al tipo de salto, al valor agregado nacional, etc), sino que incluso cuando se concuerda en la metodología, la regla para cada producto se establece de manera dispar, dependiendo del tira y afloja entre los negociadores. Es como si tras ponerse difícilmente de acuerdo en usar la yarda o el metro para establecer el paso én.un desfile organizado, luego se omitiera establecer criterios sobre la distancia entre las filas. El resultado sería catastrófico. Quizá hacia eso vamos.

Quien escribe estas líneas recuerda que se atribuye a Cocteau aquella famosa expresión de que "cuando los acontecimientos nos superan, finjamos ser sus organizadores". Si las negociaciones son individuales, cada país deberá tomar en cuenta lo que se ha negociado con anterioridad en materia de normas de origen, y así como deberá medir el impacto de las normas en lo que hace a la protección actual de su propia industria, deberá también evaluar su posible 
ORAFICO I

Paises centroamerlcanos y Móxico: dimensiones relativas (Porcentajes) $^{\mathrm{a}}$
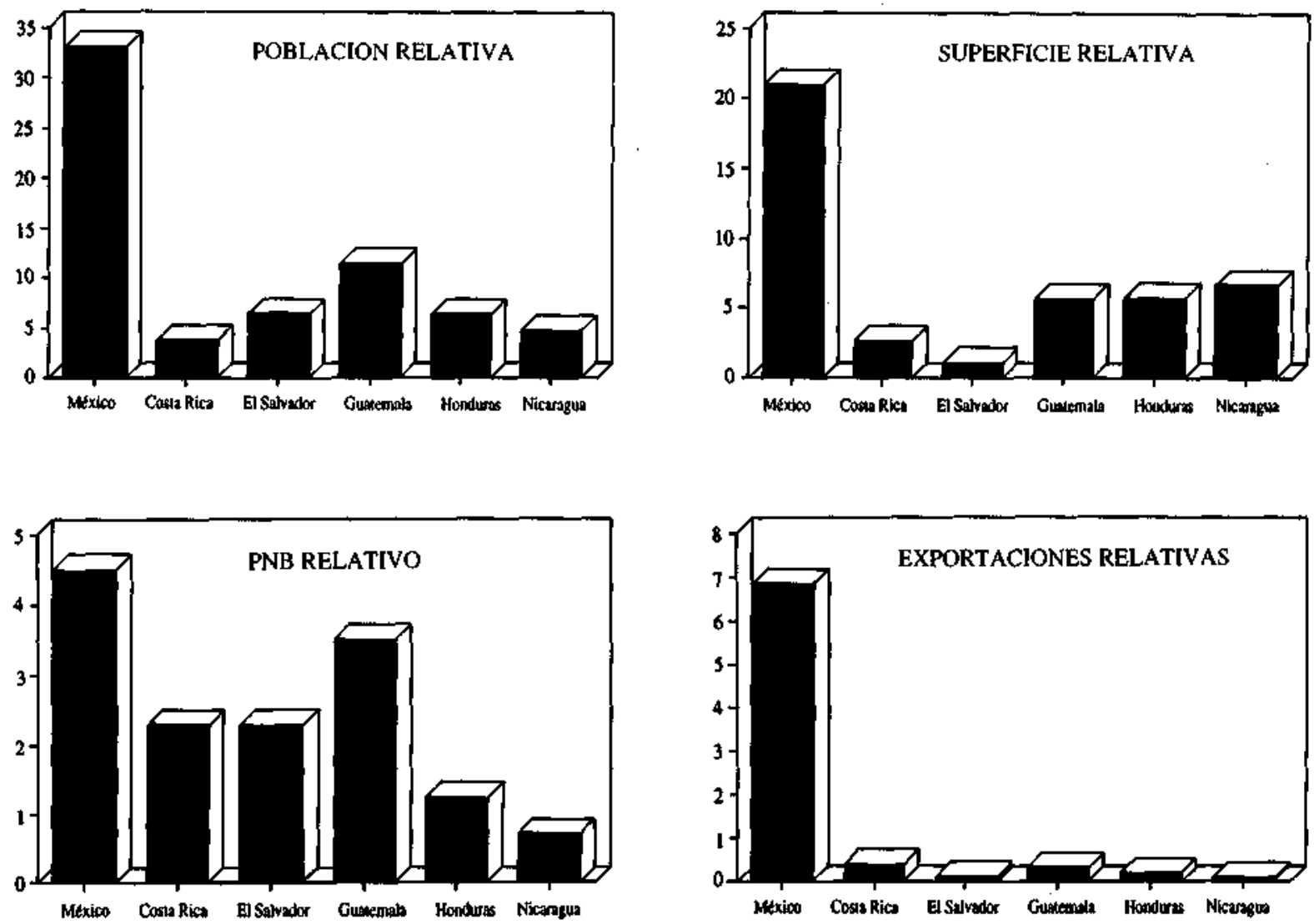

Fuente: Datos del Banco Mundial.

a Las cifras de México como porcentaje de las de Estados Unidos, y las de cada país centroamericano como porcentaje de las de México.

efecto en la futura localización de las inversiones. Dada la infinita cantidad de situaciones que pueden darse, el sistema deberá funcionar sobre la base de ensayo y error. Pero a la vez deberá hacerse hincapié en la flexibilidad de los resultados y en la posibilidad de renegociar los compromisos de manera periódica.

\section{VII}

\section{Conclusiones}

Así como el tema de las barreras no arancelarias tuvo su auge en los años sesenta y setenta por constituir una alternativa neoproteccionista frente a la desgravación arancelaria bajo la égida del GATT, y así como la defensa frente a prácticas de dumping pasa al pri- mer plano en etapas de apertura, las reglas de origen constituyen uno de los nuevos temas de la oleada de negociaciones comerciales que se han iniciado o profundizado en el continente americano desde fines de los años ochenta. Y se pueden transformar en un fac- 
tor de profunda desorganización, no solamente de los mercados, sino también de los procesos de inversión.

Las reglas de origen han sido útiles a muchos países latinoamericanos para aprovechar las ventajas unilaterales otorgadas por paises industrializados, como el Sistema Generalizado de Preferencias y la Iniciativa para la Cuenca del Caribe, y en menor grado para el cumplimiento de acuerdos de libre comercio regionales o similares. La proliferación de negociaciones a la luz del nuevo uso que se está dando a las normas de origen, negociaciones en las cuales participará inclusive Estados Unidos, obligará a reconsiderar todo el viejo esquema.

El manejo de las reglas de origen no puede verse aislado de otros elementos que apuntan a racionalizar la protección, como la cancelación de los procedimientos de reembolso en el año 2001 estipulada en diversos tratados en los que participan Estados Unidos o México, y que tenderán a hacer más homogéneas las barreras al acceso de los insumos intermedios.

Los esquemas de normas de origen negociados en lo nuevos tratados permiten extender de uno a otro país la protección en materia de insumos intermedios. Por lo tanto, las ventajas que pueden obtenerse de una zona de libre comercio no dependen ya tanto del propio sistema de protección de cada país (es decir, de que sus propios aranceles sean bajos), sino tam- bién de que las barreras de sus socios comerciales sean bajas. Por otra parte, quien gana el acceso al mercado de su socio deberá "compartir la preferencia" con quien se beneficia de la regla de origen en el otro pass.

Mientras más pequeño sea el país que negocia, más atenazado quedará si acepta reglas de origen restrictivas. Más aún, el sistema de negociaciones "uno a uno" tiene el inmenso defecto de impedir la acumulación en las reglas de origen. Esto desalienta las inversiones privadas, cuyo fomento es precisamente uno de los objetivos de cada tratado. Frente a esta situación se han levantado voces que claman por una negociación conjunta, a nivel latinoamericano, de las reglas de origen. Llegar a la precisión individual de las normas no parece una meta factible en las condiciones actuales. En cuanto a las reglas generales, es difícil que se avance más allá de lo acordado en la Ronda Uruguay, lo que tampoco dice mucho. Sería más importante trabajar sobre un concepto de asimetría que permitiera comprender que más allá de un problema de niveles de desarrollo (con el que siempre se ha manejado ese concepto), está también el del tamaño relativo de los países, que se manifiesta en profundas diferencias en la articulación de los eslabonamientos productivos. Avanzar en este tema es vital si lo que se desea es fomentar las inversiones privadas.

\section{Bibliografia}

Comision de Comercio Internacional (1994): Mexico's maquilado ras will be transformed by NAFTA, International Economic Review, Philadelphia, Economics Department, University of Pennsylvania/Osaka University Institute of Social and Economic Research Association.

Gitli, Eduardo (1994): La rama textil-vestuario en la Ronda Uruguay, el TLC de Norteamérica y la parldad para la Cuenca del Caribe, Managua, Conferencia de las Naciones Unidas sobre Comercio y Desartollo (UNCTAD)/ASDI/Programa de las Naciones Unidas para el Desarrollo (PNUD).

Krueger, Anne O. (1993): Free Trade Agreements as Protectionists Devices: Rules of Origin, NBER Working Paper, $\mathrm{N}^{\circ} 4352$, Cambridge, Ma, National Bureau of Economic Research, Inc. (NBER).
Morici, Peter (1991): Rules of origin in a North American trade accord, Toronto, Canadá University of Toronto, mimeo.

SECOF (Secretaría de Comercio y Fomento Industrial) (s/f): Reglas de origen. Monografia, Tratado de Comercio de América del Norte. $N^{\circ} 1$.

SELA (Sistema Económico Latinoamericano) (1993): Normas de origen: Análisis económico y propuestas de acción multilateral Caracas.

Serra Puche, Jaime (1992): Conclusión de las negociaciones del Tratado de Libre Comercio entre México, Canadá y Estados Unidos, texto de la presentación ante la Cámara de Senadores de México, mimeo. 
ANEXO $t$

Resultado de la negociación de libre comerclo entre Mb́xlco y Estados Unldos sobre acceso para productos mexlcanos: Pantalones de mezclilla (denim)

Clasificación

nivel de ítem

Regla de

origen
6203.42 .20

$6203.42 .40 \mathrm{~B}$

6204.62 .20

6204.62.40B

"Un cambio a la subpartida 6203.41 a 6203.49 [de varones] o a la subpartida 6204.61 a 6204.69 [de mujeres] de cualquier otro capítulo, excepto de la partida:

51.06 a 51.13 Hilados y tejidos de pelo y lana.

52.04 a 52.12 Hilados y tejidos de algodón.

53.07 a 53.08 Hilados de yute y fibras vegetales.

53.10 a 53.11 Tejidos de lo anterior.

Capítulo $\$ 4$ Hilados y tejidos sintéticos o artificiales.

55.08 a 55.16 Hilados y tejidos de fibras discontinuas.

58.01 a 58.02 Terciopelo, felpa y con bucles.

60.01 a 60.02 Otros tejidos.

"Siempre y cuando el bien esté tanto cortado como cosido o de otra manera ensamblado en territorio de una o más de las partes".

Significado: Para que un pantalón sea originario, desde el hilado en adelante deben ser también originarios. Por ejemplo, esto se complementa con las normas de origen de los tejidos de algodón 52.08 a 52.12 , en las cuales se establece que el hilado 52.05 a 52.06 debe ser originario. A su vez, en las normas del hilado se establece que el algodón debe ser originario.

Nota: Los tejidos de seda capitulo $50 \mathrm{o}$ de lino 53.09, pueden ser importados.

Producto

\begin{tabular}{c} 
Arancel base \\
$\%$ \\
\hline
\end{tabular}

Tipo de

Eliminación de

productos

originarios:

6203.42 .20

6203.42 .40 .10

6204.62 .20

6204.62 .40 .10

Cuotas y

restricciones

Arancel

especial para

productos no

originarios (cortados

y cosidos en la region)

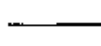

Overoles

(varones)

Otros denim

(varones)

Overoles

(mujeres)

otros denim

(mujeres)

11

Los artículos originarios no están sujetos a cuota. La restricción existente para no originarios

(consulta a nivel de 650000 docenas) se eliminará el

$1^{\circ}$ de enero de 2001. Los productos que estaban en el

Régimen Especial quedan sin cuota. Se expande la

definición de maquilado a blanqueado, teñido y lavado.

Los productos de maquilado quedan exentos de cuota.

El apéndice 6 establece como excepciones todos los productos que contengan mezclilla azul (blue denim). De esta manera no existe régimen preferencial en este caso.

Fuente: Gitli, 1994. 